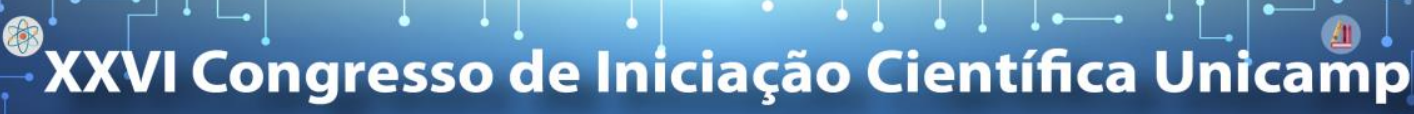

\section{O TRABALHO DOS AUXILIARES E TÉCNICOS DE ENFERMAGEM NA ATENÇÃO BÁSICA: equivalências e diferenças}

\author{
Nathalia S Monezi ${ }^{\star}$, Luciana de Oliveira, Dalvani Marques
}

\section{Resumo}

Objetivos: identificar as atividades desenvolvidas por auxiliares de enfermagem e técnicos de enfermagem na Atenção Básica em Campinas/SP e comparar com as atribuições do COFEN. Resultados: Realizadas entrevistas com 103 auxiliares de enfermagem e 46 técnicas de enfermagem. As profissionais realizavam, predominantemente, as mesmas atividades diariamente como curativos, orientações ao público, administração de medicamentos VO, EV, IM, SC E ID e acolhimento, entre outras, a exceção das atividades na sala de vacina que as auxliares de enfermagem, na maioria, referiram nunca realizarem. Conclusão: Os técnicos e auxiliares de enfermagem atualmente executam as mesmas atividades na Atenção Básica, mesmo com as mudanças ocorridas nos serviços de saúde nas últimas décadas..

Palavras-chave: Atenção Básica em saúde, Enfermagem em Saúde Pública, Educação em Enfermagem. .

\section{Introdução}

A história dos profissionais da enfermagem se origina com os atendentes de enfermagem. A partir de 1989, surgiram cursos profissionalizantes de auxiliares e técnicos de enfermagem. Em 2016, no sistema COFEN/COREN, estavam inscritos 1.927 .712 profissionais de enfermagem, sendo: auxiliares de enfermagem - 432.271, técnicos de enfermagem 1.042.128 e enfermeiros - 453.313. As atribuições de cada categoria estão definidas pelo Conselho Federal de Enfermagem (COFEN). Assim, como cada categoria profissional possui um processo de formação próprio.

Os objetivos deste estudo foram identificar as atividades desenvolvidas por auxiliares de enfermagem e técnicos de enfermagem na Atenção Básica em Campinas/SP e comparar com as atribuições do COFEN.

\section{Resultados e Discussão}

Estudo quantitativo, realizado por entrevistas com 103 auxiliares de enfermagem e 46 técnicas de enfermagem. A maioria das profissionais eram casadas, com filhos e referiram se atualizar através da internet. As auxiliares já eram formaram no curso técnico de enfermagem e trabalhavam no atual serviço entre 1 a 5 anos e de 16 a 20 anos. Enquanto, a maioria das técnicas já trabalharam como auxiliares e atuavam no atual serviço de 1 a 5 anos.

Em relação as práticas desenvolvidas, ambas as profissionais realizavam, predominantemente, as mesmas atividades diariamente como curativos, orientações ao público, administração de medicamentos VO, EV, IM, SC E ID e acolhimento, entre outras. Destacam-se as atividades na sala de vacina como realizadas diariamente pelas técnicas de enfermagem, enquanto as auxiliares, na maioria, referiram nunca realizarem.

Em comparação com as atribuições do COFEN, observou-se que algumas das atividades diárias não são atribuições simples e repetitivas como atribuído as auxiliares de enfermagem.
Figura 1. Relação das atividades dos auxiliares e técnicos de enfermagem

\begin{tabular}{l|cr|rc} 
Variaveis & \multicolumn{2}{|c|}{ Auxiliares } & \multicolumn{2}{c}{ Técnicos } \\
\hline $\begin{array}{l}\text { Realização de } \\
\text { Curativos }\end{array}$ & $\mathbf{N}$ & $\%$ & $\mathbf{N}$ & $\%$ \\
$\begin{array}{l}\text { Nunca } \\
\text { diariamente }\end{array}$ & 20 & 19,42 & 8 & 17,39 \\
\hline $\begin{array}{l}\text { Administração de } \\
\text { Medicamentos }\end{array}$ & $\mathbf{N}$ & $\%$ & $\mathbf{N}$ & $\%$ \\
$\begin{array}{l}\text { EV,IM,SC,ID } \\
\text { Nunca }\end{array}$ & & & & \\
Diariamente & 47 & 45,63 & 32 & 69,57 \\
\hline $\begin{array}{l}\text { Controle de frio } \\
\text { Nunca }\end{array}$ & $\mathbf{N}$ & $\%$ & $\mathbf{N}$ & $\%$ \\
Diariamente & 66 & 64,08 & 18 & 39,13 \\
& 18 & 17,48 & 21 & 45,65
\end{tabular}

\section{Conclusões}

Mesmo com as mudanças ocorridas nas últimas décadas, é difícil observar distinção entre as práticas dos técnicos e auxiliares de enfermagem. Aparentemente, isto ocorre por diferentes motivos, desde a carga excessiva de atividade e o número reduzido de profissionais, até a criação recente do cargo de técnico de enfermagem.

\section{Agradecimentos}

Agradeço ao PIBIC pela oportunidade de ampliar meus conhecimentos. À Prof ${ }^{a}$ Dalvani pela orientação e paciência e ao companheiro Juliano pelo amor e carinho.

\footnotetext{
1 Bezerra MM, Guerra DR e Guedes MVC. Atendente de enfermagem: Por quê? Até quando? Rev. Bras. Enferm. 1998 jan/mar; 51 (1): 77-92.

2 COFEN. Conselho Federal de Enfermagem. Quadro quantitativo das categorias dos profissionais de enfermagem [Acesso em 27 mar 2017]. Disponível em http://www.cofen.gov.br/enfermagem-em-numeros

3 Brasil. Lei n.7498/86, de 25 de junho de 1986. Conselho Federal de Enfermagem. Regulamentação do exercício da Enfermagem e de outras providencias [Acesso em 27 mar 2017]. Disponível em: http://www.cofen.gov.br/lei-n-749886de-25-de-junho-de-1986_4161.html.
} 